\title{
Decentralizing decision making in modularization strategies: Overcoming barriers from dysfunctional accounting systems
}

\author{
Poul Israelsen ${ }^{a, *}$, Brian Jørgensen ${ }^{b}$ \\ a Aalborg University, Centre for Industrial Production, Fibigerstraede 16, DK-9220 Aalborg, Denmark \\ b Department of Business Studies, Aarhus School of Business, Aarhus University, Fuglesangs Allé 4, DK-8210 Aarhus V, Denmark
}

\section{A R T I C L E I N F O}

\section{Article history:}

Received 22 July 2009

Accepted 21 December 2010

\section{Keywords:}

Modularization

Accounting

Cost allocation

Decision rule

Decentralization

\begin{abstract}
A B S T R A C T
Research on product modularity is dominated by an operations management (OM) perspective, through which numerous models to predict optimal modularization strategies have been developed. However, we argue that implementation of these predictions is hampered by prevailing project accounting systems which distorts the economic effects of modularization at the level of the individual product. This has the implication that decisions on modularization can only be made by top management if decision authority and relevant information are to be aligned. To overcome this problem, we suggest a solution that aligns the descriptions of the economic consequences of modularization at the project and portfolio level which makes it possible to decentralize decision making while making sure that local goals are congruent with the global ones in order to avoid suboptimal behaviour.
\end{abstract}

(c) 2010 Elsevier B.V. All rights reserved.

\section{Introduction}

Rapid product development is key to sustainable competitive advantage, both in terms of satisfying the seemingly ever increasing customer demand for variety and to keep competitors off the market. Product development is, however, a rather resource demanding activity, and speeding up this process will therefore typically incur more costs. In addition, even though empirical results are somewhat ambiguous (cf. Anderson, 1995), it is generally assumed that increased product variety has a negative impact on company costs (e.g. Miller and Vollman, 1985; Banker et al., 1995; Kaplan and Cooper, 1998). With increased product portfolio heterogeneity the company will typically have to source, manufacture, and sell in smaller batches and the support functions of the company will typically have to be expanded to accommodate the increased internal demand for activities such as planning, change over, quality testing, etc.

Fisher et al. (1999) suggest two general approaches to handle increased costs caused by increased variety. One approach is process oriented and the other product oriented. Whereas the process approach focuses on introducing flexible manufacturing equipment, the product approach is concerned with designing products that make it possible to offer variety at low costs. Product modularity, i.e. using the same components (modules) in different

\footnotetext{
* Corresponding author. Tel.: +45 9940 7319; fax: +45 99403040.

E-mail addresses: pi@production.aau.dk (P. Israelsen), bvj@asb.dk (B. Jørgensen).
}

products and thereby allowing for variety at low costs (Ramdas, 2003), is one example of the latter approach. The concept of modularity varies across literature (Fixson and Clark, 2002; Fixson, 2005; Salvador, 2007), however, we use it equivalently to component sharing (Ramdas et al., 2003) and component commonality (Labro, 2004). Product modularity is not a new phenomenon (see Starr, 1965, 2010). However, it seems to attract growing attention. Recent years have seen a rising number of publications on this (e.g. Kim and Chhajed, 2000; Baldwin and Clark, 2000; Nobelius and Sundgren, 2002; Salvador et al., 2002; Doran, 2003; Zhou and Grubbström (2004); Antonio et al., 2007; Doran et al., 2007; Brun and Zorzini, 2009; Brun et al., 2009; Jans et al., 2008; Gomes and Joglekar, 2008) and it is claimed that companies across industries increase their use of modularity (e.g. Sanchez, 1999; Kim and Chhajed, 2001). Indeed, according to Heikkilä et al. (2002) modularity has become one of the most discussed issues in product development, technology, and business management.

As argued by Labro (2004), modularity or commonality has primarily been researched from an operations management (OM) perspective, whereas there are only few contributions from management accounting researchers. This is somewhat surprising considering the apparent relevance for this domain, given the fact that surveying the relevant literature, it is evident that product modularity is supported by an economic rationale. OM research has, for example, shown that modularizing companies may enjoy increased economies of scale (Krishnan and Gupta, 2001), reduced demand for support activities (Thonemann and Brandeau, 2000) and reduced investment in tools (Fisher et al., 1999). Other more soft approaches have identified reduced assembly time due to 
learning curve effects (Nobelius and Sundgren, 2002), and increased market share (Nobeoka and Cusumano, 1997; Sanderson and Uzumeri, 1995). The arguments in this paper are developed from a management accounting perspective, but based on insights from OM research.

Ramdas et al. (2003) present three organizational structures for approaching modularity: the coordinated projects approach, the project-by-project approach and an intermediate partially coordinated approach, i.e. a mix of central and local decisions. They develop a model that predicts the coordinated projects approach to offer the most cost-efficient path. Ramdas et al. (2003) suggest that model implementation may be challenged by designers who perceive the use of such a model as a distraction from more important development work. In this paper we add another challenge. We argue that the implementation or continued support of the optimal strategies predicted by the OM models will encounter difficulties in practise - not because they are formal or because they must necessarily rely on a set of assumptions, but because companies' accounting systems will act as barriers to implementation.

We base our discussion on Ramdas et al. (2003), but we believe that our claim is generally valid across OM models-irrespective of the correctness of the model because if the accounting systems used in practise do not provide information that supports the OM model prediction, implementation will be impeded. This is the case in many companies where the accounting system is set up to account for the individual projects' performance. Unit costs of the common components probably differ from the cost of the unique component being substituted-to the benefit of some projects and detriment of others-and development cost of the common component is split between participating projects in a heuristic manner. Consequently, the economic consequences of modularization are not described adequately in the individual projects' accounts and decisions to modularize or not should be based on the aggregate consequences across all participating projects only. This has the implication that decisions must be made by top management if decision authority and decision information are to be aligned. In this situation all projects should be coordinated centrally, corresponding to Ramdas et al.'s coordinated project approach. This is probably infeasible, since "[a]ttention is the chief bottleneck in organizational activity, and the bottleneck becomes narrower and narrower as we move to the top of the organizations" (Simon, 1976:294). The objective is therefore to change the project accounting system so that it does not act as an obstacle to decentralization and in such a way that it encourages project managers to make local decisions in congruence with global goals. We develop the boundaries of such a system and within this a rulebased profit and cost allocation approach that makes this possible.

The remainder of the paper is organized as follows: Section 2 presents a review of OM literature on economic decision making for modularity. In Section 3 we develop a changed project accounting system that makes decentralization of modularization decisions possible and illustrate the idea by an empirical example in Section 4. In Section 5 we discuss some practical challenges and Section 6 concludes the paper.

\section{OM models and modularity}

OM researchers have enriched the field with a number of formal models that aim to provide optimal solutions to a wide set of problems related to decision making in product modularity. The models are seemingly becoming more and more comprehensive: from the initial narrow focus on inventory costs, over more elaborate, full-cost models to recent developments of models which include both cost and revenue effects.
Some of the earliest contributions focus on the effect from modularization on holding costs. The classical argument is that safety stock levels may be reduced for a given service level (Collier, 1982) due to risk pooling (Eynan and Rosenblatt, 1996; Thonemann and Brandeau, 2000). In a similar vein, companies may enjoy reduced holding costs on work in progress inventories due to delayed differentiation (Lee and Tang, 1997; Swaminathan and Tayur, 1999). Balakrishnan and Geunes (2000) provide a new perspective on the substitution options that a production planner may benefit from if products are based on modularity. For example, low demand components may be economically substituted with higher demand components of equal or higher functionality. This is relevant in industrial situations where seasonal fluctuations characterize demand. Hillier (2002) suggests that the more costly common modules should be used as safety stock and shows that such a strategy outperforms integral products with no commonality or, at the other extreme, products with "pure commonality".

Another classical cost consideration in modularization is the trade-off between development costs and unit costs: increasing investments in the product development stage may result in decreased unit costs in the manufacturing stage. In determining this balance, both platform development costs, product-unique development costs, unit costs and over-design costs (a part of the unit costs) should be included (Krishnan and Gupta, 2001); only the specific situation will determine the optimal strategy. Krishnan et al. (1999) develop a model to optimize decision making in what they call the aggregate-planning phase, i.e. the strategic decisions taken before a platform and set of products to be developed are determined. They investigate the trade-off between increased platform development costs and decreased development costs at the individual product level.

Another stream of research addresses the problem from a "total-cost" perspective with a view to developing more comprehensive models. Thonemann and Brandeau (2000) have developed a model to determine the optimal level of commonality considering both direct and indirect costs and development costs. A model created by Ramdas et al. (2003) addresses the problem from a tactical perspective. This model is tested on three different scopes of product modularity: aggregate planning, project-byproject and an intermediate scope, where some architectural decisions are made at a central planning office and some are made locally by project management. They find that aggregate planning is the most profitable scope, but also acknowledge that the hybrid, intermediate scope, is the one most likely to be found in industrial settings.

In many situations both income and cost effects must, however, be included to analyze the profitability potential of modularity. As Fisher et al. (1999) argue, minimizing costs will not necessarily lead to optimized profitability. If products are based on platforms or common modules, companies risk that products cannibalize each other. Robertson and Ulrich (1998) point out that companies need to pursue a balance between commonality and distinctiveness and suggest that we should differentiate between internal and external commonality according to whether the commonality is visible to the customer or not. As Heikkilä et al. (2002:24) put it, "an Audi owner knowing that a considerable part of the components in his car are the same as those used by Skoda might not be totally happy with the situation". This accentuates the relevance of yet another trade-off, namely the one between cost and revenue interactions. This is modelled by Kim and Chhajed (2000), Desai et al. (2001) and Ramdas and Sawhney (2001), and more recently by Heese and Swaminathan (2006) arguing that it is essential to take into account interactions between commonality, production cost, quality emphasis per customer segments, and the company's effort to reduce production costs in order to optimize the cost and revenue effects of modularization. 
No matter the rigour of these models, the predictions that they make will have difficulty getting implemented simply because the information produced by the companies' accounting systems will not support such plans.

\section{Changed project accounting}

For a module to be used in more than one product, some degree of over-specification is most probably needed; i.e. the module must contain more functionality than is needed should the module be used in one product only. Designing and producing the over-specified module influences several categories of cost; we identify four of which the net effect in general cannot be determined. First, it probably has a unit cost impact in that it consumes more material and direct labour. Since the module is over-specified, it is presumably more costly than otherwise unique-to-one-product solutions. Actually, it is - ceteris paribus - sometimes expected that the module is at least as costly as the costliest of the otherwise unique-to-one-product solutions (Thyssen et al., 2006). Thus, all products using the module except the one product using all module functionality (and such a product may not exist) - will be more costly due to the overspecification. On the other hand, removing "ceteris paribus" one may argue that common modules become less costly due to economies of scale from, for example, procurement discounts and learning effects. Second, it probably also has a batch cost effect due to the fact that over-specified modules may take longer to test, and set-up costs may also be higher for more complex modules. However, these effects may be moderated by less total batches among cooperating product as a result of fewer subassembly variants to be produced. Third, it has the extra upfront investment cost from more laborious design work, developing the module to make it fulfil the needs of all products which will use it. Again we have an opposing effect due to the decreased amount of modules to be developed. And fourth, we have information cost in determining the module possibilities and associated cost estimates. (The implication of the fourth effect is postponed to section 5.) Although, as mentioned, we cannot a priori know the net effect of these cost changes we assume that the project managers can make reliable estimates in the company-specific case.

What is obvious from the above is that sharing of modules creates cost interdependencies among participating products, and this has implications for the way we can account for the economics of the individual product project within a portfolio of projects; simple rules-of-thumb allocations often will not do (cf. examples in Section 5). Sharing of modules might also create revenue interdependencies but we leave this possibility out in the following.

Assume that we are in a planning situation where we have a fixed and known number of products, $N$, to be concurrently developed, and we have reliable estimates of the demand for each product. We also presume that there are a number of technically feasible ways of designing and producing each of these products sharing modules to some extent. Furthermore, we assume that we have estimates of development costs for each component and module, unit level costs per unit and batch cost for each component and module. These initial circumstances are similar to the ones in the situation investigated by Ramdas et al. (2003). As previously discussed, they show that cost minimizing at the portfolio level leads to lower costs than a project-by-project minimizing effort due to the ability of the first procedure to make trade-offs across the entirety of projects. Our concern is twofold. First, in a situation with beneficial trade-offs possible across product projects we need this to be reflected in the individual project accounts and not just at the portfolio level since this would leave relevant information only at the top; and this is the situation with normal (i.e. product-focused) project accounting systems. And this change of project accounts should be done no matter whether the company pursues central or local decisionmaking (or some mix) concerning modularization. Second, in dealing with the first concern, i.e. constructing a changed project accounting system, it is then possible to tie responsibility accounting to the individual product project managers and encourage them to cooperate with one another in enhanced modularization efforts to improve both local and global profit.

Using the plan data each project manager can minimize costs in his or her project. We take as a point of departure that each project manager will do so, and make the first projection on project profitability with these inputs. However, the project manager knows that cooperating with other project managers might bring down the sum of costs across projects. This potential is known by top management too, of course. We suggest that management should therefore induce such cooperative behaviour by introducing some profit and cost allocation procedure which should ensure that project managers, on their own initiative, will engage in investigating modularization across projects even further, and while taking into account technical feasibility constrains on the enhanced module (i.e. Ramdas et al.'s (2003) system-to-product, component-to-product and interactivity constraints) implement these possibilities if both global and local profits can be expected to increase. This can be left decentralized only if individual project accounts are organized to reflect the economics at the portfolio level (our first concern mentioned above). In this endeavour we expect our project managers to be risk-neutral, profit-seeking individuals whose performance is evaluated on the net present value, NPV, of their projects.

A simple example will illustrate what we will work out formally and demonstrate later with a more elaborate case. Suppose that three products can use a common module. If only two products use the module, the profit from that group is 300 and the profit from the standalone product is 40 . If instead all three use the common (now more elaborate) module, overall profit is 400 . The 60 increase in total profit is due to the net effect of saved cost in not developing the standalone manager's unique component, increased cost in developing the now more overspecified common component, and changed unit and batch costs. To induce the standalone project manager to use the common module, he should get more than 40 in the new allocation. On the other hand, if the new allocation provides him a total profit of more than 100 , this is also a problem.

The formal way: assume that a project $j$ belongs to a portfolio of projects, $N$, for which it is technically feasible to use a common module $\mathrm{M}$ (more or less advanced depending of the number of participating projects to accommodate). To actually include project $j$ in the group of products using module $\mathrm{M}$, the project must contribute to the profitability of the portfolio using that module (the 60 in the simple example), i.e.

$$
\begin{gathered}
\Delta^{\mathrm{AM}(\mathrm{M})} P_{j}=\left(\sum_{i=1}^{n}{ }^{\mathrm{AM}(\mathrm{M})} P_{i}^{\mathrm{BA}}-C^{\mathrm{M}(\mathrm{M})}\left(p_{1}, p_{2}, \ldots, p_{j}, \ldots p_{n}\right)\right) \\
-\left(\sum_{i=1}^{j-1}{ }^{\mathrm{AM}(\mathrm{M})} P_{i}^{\mathrm{BA}}+\sum_{i=j+1}^{n}{ }^{\mathrm{AM}(\mathrm{M})} P_{i}^{\mathrm{BA}}+{ }^{\mathrm{BM}} P_{j}\right. \\
\left.-C^{\mathrm{M}(\mathrm{M})}\left(p_{1}, p_{2}, \ldots, p_{j-1}, 0, p_{j+1}, \ldots p_{n}\right)\right)>0
\end{gathered}
$$

$\hat{1}$

$$
\begin{aligned}
& \Delta^{\mathrm{AM}(\mathrm{M})} P_{j}=\left(\sum_{i=1}^{n}{ }^{\mathrm{AM}(\mathrm{M})} P_{i}^{\mathrm{BA}}-\sum_{i=1}^{j-1}{ }^{\mathrm{AM}(\mathrm{M})} P_{i}^{\mathrm{BA}}-\sum_{i=j+1}^{n}{ }^{\mathrm{AM}(\mathrm{M})} P_{i}^{\mathrm{BA}}-{ }^{\mathrm{BM}} P_{j}\right) \\
& -\left(C^{\mathrm{M}(\mathrm{M})}\left(p_{1}, p_{2}, \ldots, p_{j}, \ldots p_{m}\right)-C^{\mathrm{M}(\mathrm{M})}\left(p_{1}, p_{2}, \ldots, p_{j-1}, 0, p_{j+1}, \ldots p_{m}\right)\right)>0
\end{aligned}
$$




\section{Notation:}

$i \quad$ index of projects $(1,2, \ldots, j, \ldots n)$

$p_{i} \quad$ project $i$

$P_{i} \quad$ profit of project $i$, i.e. NPV of $i$, where $i \in N$

$N$ portfolio of projects sharing a common module, here module $\mathrm{M}$

BM before modularization

$\mathrm{AM}(\mathrm{M})$ after modularization (using module $\mathrm{M}$ )

BA before allocation of any costs of developing and producing the common module

$\mathrm{C}^{\mathrm{M}(\mathrm{M})}\left(p_{1}, p_{2}, \ldots, p_{j}, \ldots p_{n}\right)$ cost of common module $\mathrm{M}$, i.e. development costs plus aggregate unit and batch costs to accommodate the needs of projects using the common module.

A remark on our notation: superscript in front of project profit, $P_{j}$, indicates whether it is before or after modularization and with which module, (here M). Superscript after $P_{j}$ indicates to which degree cost of the common module has been allocated to (deducted from) profit of project $j$. Consequently, ${ }^{\mathrm{AM}(\mathrm{M})} P_{i}^{\mathrm{BA}}$ denotes the profit of project $i$ after it has been modularized using $\mathrm{M}$ and has had its costs reduced due to not having to develop and manufacture the unique component being substituted by the common module, but before allocation of any cost of developing and producing the common module. ${ }^{\mathrm{AM}(\mathrm{M})} P_{i}^{\mathrm{BA}}$ therefore is always (much) higher than the project's profit before modularisation, ${ }^{\mathrm{BM}} P_{i}$, which includes costs of developing and producing the unique component contemplated to be replaced.

If we assume as a prerequisite that the module implementation causes no cannibalization between products, i.e. no revenue effect amongst the modularized products, the first parenthesis in (1) equals the benefit of modularization for all the cost savings of not having to develop and produce the substituted unique component of project $j$. The second parenthesis is the total differential cost of developing and producing more units of a probably more over-specified common module to also accommodate project $j$. The amount in both parentheses is positive and therefore the first amount should outweigh the second to satisfy statement (1).

Projects in $N$ satisfying (1) form a group of projects, $N^{E}$, for which it is economically beneficial to use module $M$. If we denote the number of elements in $N^{E} m$, it follows that $N^{E} \subseteq N, m \leq n$, and the profit increase across projects in $N^{E}$ can be written as

$$
\begin{aligned}
\Delta^{\mathrm{AM}(\mathrm{M})} P= & \sum_{i=1}^{m}{ }^{\mathrm{AM}(\mathrm{M})} P_{i}^{\mathrm{BA}}-C^{\mathrm{M}(\mathrm{M})}\left(p_{1}, p_{2}, \ldots, p_{j}, \ldots p_{m}\right) \\
& -\sum_{i=1}^{m}{ }^{\mathrm{BM}} P_{i}>0 ; i \in N^{E}
\end{aligned}
$$

In developing a profit and cost allocation scheme that works in decentralized setting we need that none of the managers of the participating project in $N^{E}$ are less well off than as standalone projects (the 40 in the simple example). This lower bound constraint is expressed in (3)

${ }^{\mathrm{AM}(\mathrm{M})} P_{i}^{\mathrm{AAT}}-{ }^{\mathrm{BM}} P_{i} \geq 0$

Notation:

AAT after allocation of $p_{i}$ 's share of Total cost of modularization, i.e. after allocation of $p_{i}$ 's share of $\mathrm{C}^{\mathrm{M}(\mathrm{M})}$

According to Eq. (1) all projects using module M should contribute to increased profit. Under normal circumstances development cost will be an increasing function of the number of projects that the common module should accommodate. On the other hand, differential cost of manufacturing is influenced by at least two opposing effects, e.g. a cost decreasing effect from economies of scale and a cost increasing effect from overspecification. Using Eq. (1) makes the procedure robust to whatever effect might be dominating as long as the net effect can be assessed in the specific situation. Generally speaking, the lower the development cost and costs per unit, and the higher the volume of the unique-to-one-product solution the more marginal a candidate the product will be in participating in the common module solution (cf. Thyssen et al., 2006). If we arrange the contributing projects in descending order of contributing profit, $\Delta^{\mathrm{AM}(\mathrm{M})} P_{i}$, we can formulate another constraint to the way in which the total profit increase can be split between the participating projects. At any given point in incorporating additional projects in the use of the common module, the marginal project incorporated cannot have more profit increase allocated than the marginal profit increase of the portfolio of participating projects caused by this project (the 60 in the simple example). Otherwise project managers of previously included projects will not accept the marginal projects in decentralized settings. This upper bound constraint is formulated in (4) using the definition of $\Delta^{\mathrm{AM}(\mathrm{M})} P_{j}$ in (1)

${ }^{\mathrm{AM}(\mathrm{M})} P_{j}^{\mathrm{AAT}}-{ }^{\mathrm{BM}} P_{j} \leq \Delta \Delta^{\mathrm{AM}(\mathrm{M})} P_{j}$

Within these constraints we next formulate an allocation procedure.

\subsection{Rule-based allocation procedure}

A variety of procedures can be devised to allocate the costs of developing and manufacturing the common module among participating projects; a solution has many degrees of freedom. Any procedure that obeys the upper and lower bound constraints will do since the constraints ensure incentive compatibility between global and local goals, and consequently that no project manager is less well off than before modularization whilst at least one is better off if the modularization effort is profitable. Hence, the constraints meet the Pareto criterion.

Below we develop a rule-based procedure, as opposed to a procedure using negotiations between project managers. Our procedure allocates the marginal profitability of a participating project to this particular project. The allocation runs as procedure $A$.

Procedure A:

If statement (2) subject to (1) holds we allocate the profit increase to the contributing project, i.e. using (4) with the equal sign ${ }^{\mathrm{AM}(\mathrm{M})} P_{i}^{\mathrm{AAT}}={ }^{\mathrm{BM}} P_{i}+\Delta^{\mathrm{AM}(\mathrm{M})} P_{i} ; i \in N^{E}$

Hence (5) is the target profit for project $i$ which will be used to determine the allocation of the project's share of total costs of the module.

First we allocate the unit level cost of module $M$ to the projects proportional to the number of units used by each project (in case of batch cost think of these allocated to the unit level). If an individual project $j$ becomes less profitable than the target profit, project $j$ needs to have allocated a lump sum credit to make it hit the target, i.e.

If $\quad{ }^{\mathrm{AM}(\mathrm{M})} P_{j}^{\mathrm{AAU}}<{ }^{\mathrm{BM}} P_{j}+\Delta^{\mathrm{AM}(\mathrm{M})} P_{j}$

Then $j \in L^{\text {ump }}$

Notation:

$L^{u m p} \quad$ the group of projects needing lump sum allocation AAU after allocation of $p_{j}$ 's share of all Unit cost of the common module 
The lump sum to be credited type $L^{u m p}$ projects is

$\left({ }^{\mathrm{BM}} P_{j}+\Delta \Delta^{\mathrm{AM}(\mathrm{M})} P_{j}\right)-{ }^{\mathrm{AM}(\mathrm{M})} P_{j}^{\mathrm{AAU}} ; j \in L^{u m p}$

Hence, the total lump sum credited all type $L^{u m p}$ projects is

$\sum_{j \in L^{u m p}}\left(\left({ }^{\mathrm{BM}} P_{j}+\Delta^{\mathrm{AM}(\mathrm{M})} P_{j}\right)-{ }^{\mathrm{AM}(\mathrm{M})} P_{j}^{\mathrm{AAU}}\right)$

The lump sums allocated type $j$ projects are financed by an extra cost allocation to type $i$ projects not belonging to $L^{u m p}$, $i \notin L^{u m p}$. Hence, total amount of costs to be debited type $i$ projects is development costs of the common module plus the amount credited type $L^{u m p}$ projects

$C^{\mathrm{M}(\mathrm{M})}-C^{\mathrm{MU}(\mathrm{M})}+\sum_{j \in L^{u m p}}\left(\left({ }^{\mathrm{BM}} P_{j}+\Delta^{\mathrm{AM}(\mathrm{M})} P_{j}\right)-{ }^{\mathrm{AM}(\mathrm{M})} P_{j}^{\mathrm{AAU}}\right)$

Notation:

$\mathrm{C}^{\mathrm{MU}(\mathrm{M})}$ total unit cost of module $\mathrm{M}$

Each project $i \notin L^{u m p}$ will show a profit before allocation of the amount shown in (9) at ${ }^{\mathrm{AM}(\mathrm{M})} P_{i}^{\mathrm{AAU}}$. If we deduct the target profit in (5) from this, we get the share of (9) to allocate project $i$

${ }^{\mathrm{AM}(\mathrm{M})} P_{i}^{\mathrm{AAU}}-\left({ }^{\mathrm{BM}} P_{i}+\Delta^{\mathrm{AM}(\mathrm{M})} P_{i}\right) ; i \notin L^{u}$

This ends procedure $A$.

We might have situations with competing suggestions for modularization in subgroups of $N$, i.e. suggestions competing with $\mathrm{M}$, which among the subgroups are mutually exclusive but all profitable. That is subgroup $N 1$ sharing a common module M1, subgroup $N 2$ sharing module $\mathrm{M} 2$ and subgroup $N k$ sharing module Mk, where $N 1 \subset N, N 2 \subset N, \ldots, N k \subset N$, and $N 1 \cap N 2 \cap \ldots \cap$ $N k=\emptyset$. If we use statement (2) subject to (1) on M1/N1, M2/N2, and ... Mk/Nk, we have the situation in either (11) or (12)

$\Delta^{\mathrm{AM}(\mathrm{M} 1)} P+\Delta^{\mathrm{AM}(\mathrm{M} 2)} P+\ldots+\Delta^{\mathrm{AM}(\mathrm{Mk})} P>\Delta^{\mathrm{AM}(\mathrm{M})} P$

$\Delta^{\mathrm{AM}(\mathrm{M} 1)} P \wedge \Delta^{\mathrm{AM}(\mathrm{M} 2)} P \wedge \ldots \wedge \Delta^{\mathrm{AM}(\mathrm{Mk})} P \wedge \Delta^{\mathrm{AM}(\mathrm{M})} P>0$

$\Delta^{\mathrm{AM}(\mathrm{M} 1)} P+\Delta^{\mathrm{AM}(\mathrm{M} 2)} P+\ldots+\Delta^{\mathrm{AM}(\mathrm{Mk})} P \leq \Delta^{\mathrm{AM}(\mathrm{M})} P$

$\Delta^{\mathrm{AM}(\mathrm{M} 1)} P \wedge \Delta^{\mathrm{AM}(\mathrm{M} 2)} P \wedge \ldots \wedge \Delta^{\mathrm{AM}(\mathrm{Mk})} P \wedge \Delta^{\mathrm{AM}(\mathrm{M})} P>0$

If (11) is true, the subgroup profit-improving modules are in the aggregate better than module $\mathrm{M}$, and the subgroup modules should be implemented instead of $\mathrm{M}$. The mechanism in allocating profit and cost to projects within each subgroup follows procedure A. If, on the other hand, profit increase using the more encompassing module $\mathrm{M}$ is higher as in (12), $\mathrm{M}$ is the preferred module to use. (If the equal sign prevails, we are formally indifferent to whether subgroup modules or $\mathrm{M}$ is implemented.) To make sure that this is incentive compatible in decentralized settings, the profit increase that would have been allocated to each project using subgroup modules needs to form lower bounds on the allocation using $M$, i.e.

${ }^{\mathrm{AM}(\mathrm{M})} P_{i}^{\mathrm{AAT}}>{ }^{\mathrm{AM}(\mathrm{Mx})} P_{i}^{\mathrm{AAT}} ; \mathrm{Mx} \in\{\mathrm{M} 1, \mathrm{M} 2 \ldots$, or $\mathrm{Mk}\}$
If statement (12) is true, we need to run a profit allocation procedure prior to procedure A, call it procedure *A. Actually procedure *A is no more than running $A$ for each of the subgroups. The resulting profit and cost allocation per project is then used as input to procedure A using module $M$. Let project profits after subgroup allocations be denoted ${ }^{\mathrm{BM} *} P_{j}$. In procedure A Eq. (5) using ${ }^{\mathrm{BM} *} P_{j}$ makes sure that no project will have its profit deteriorate from what could be achieved by cooperating in a subgroup.

\section{An empirical example}

In the following we demonstrate our rule-based allocation procedure with an example based on the challenges faced by a company that develops high-tech, analytical instruments. The company took part in a wider research project on the organizational, management accounting and management control implications of modularization. Some years ago the company decided to change product development strategy and base the future on modular products. The organizational processes in $R \& D$ and production were adapted to this new approach, but the company continued to struggle with the accounting structures. One of the accounting challenges faced by the company was a perfect match to what is discussed above. Specifically, the company was in the process of developing new instruments. The instruments were developed by separate project teams and intended for completely different markets. However, all instruments needed a four-button user interface. Therefore it was suggested to develop a common controller module which was able to meet the requirements from all instruments and to substitute the current plans of developing a number of unique controller solutions. This suggestion seemed intuitively sound, but two problems appeared:

1) Increased unit costs due to over-specification. The project managers for projects experiencing a rise in unit costs resisted because it decreased the financial viability of their instruments.

2) Development costs of the module. How should this burden be shared between projects; what proportion should be allocated each project?

Interviews with project managers and the board of directors (including the CEO, CFO and Head of R\&D) clearly signalled that these problems were common across their modularization projects. We hypothesize that most companies embarking on a modularization strategy will have to deal with the challenge of how to subsidize products suffering from increased unit costs due to over-specification and how to allocate common development costs to individual products.

The data input is presented in Table 1 (numbers have been disguised). The unit and development costs are those relevant for decision making, i.e. those that will disappear if the modularization programme is ratified. For example, developing a unique

Table 1

Cost and volume data relevant to the modularization decision.

Before modularization

\begin{tabular}{|c|c|c|c|c|c|c|c|c|}
\hline & $p_{1}$ & $\boldsymbol{p}_{2}$ & $\boldsymbol{p}_{3}$ & $\boldsymbol{p}_{4}$ & $p_{5}$ & $p_{6}$ & Sum $p_{1}-p_{6}$ & New $p_{1-6}$ \\
\hline Cost per unit & 18 & 16 & 15 & 14 & 12 & 10 & & 13.5 \\
\hline \# of units & 25,000 & 30,000 & 20,000 & 25,000 & 30,000 & 35,000 & 165,000 & 165,000 \\
\hline Development cost & 500,000 & 450,000 & 400,000 & 350,000 & 300,000 & 100,000 & $2,100,000$ & $2,012,500$ \\
\hline Sales price per unit & 50 & 45 & 40 & 35 & 30 & 25 & & \\
\hline
\end{tabular}


controller for project $p_{3}$ is estimated to cost 400,000 . The unit costs are expected to be 15 for each of the 20,000 units needed during the budgeted product life cycle. The common controller module will cost 2,012,500 to develop, and the unit costs will be 13.5 per unit. This means that if participating in the modularization, $p_{5}$ and $p_{6}$ will have to tolerate a unit cost increase, and all six projects will have the common development costs to share.

Using these numbers, Table 2 shows: (i) profit per project before modularization, (ii) the sum of these profits and (iii) a comparison of this sum total to the total profit of projects using the common module (M). This indicates the benefits of using the common module, showing an aggregate profit increase of 150,000 or $9.0 \%$.

Table 3 shows how each of the projects contributes to increased profit using a more and more elaborate (multifunctional and over-specified) module produced in increasing volume and saving more and more product-unique development costs, but also leading to rising costs of developing the common module. This corresponds to the right-hand side of statement (1). Since the split between the cost-changing effects have no bearing on the allocation procedure, only the aggregate incremental profit has, individual effects are not shown in Table 3. Projects are named $p_{1}$ to $p_{6}$ in decreasing order of marginal profit contribution.

Table 4 provides the calculation of the lump sum to be allocated (and the projects to be credited, here only project $p_{6}$ ) as well as the debits due to common module development costs plus aggregate lump sum. Table 4 shows how we first deduct from project revenues total unit costs found by multiplying the project's volume with the cost per unit of the common module. The unique development cost (concerning the component module $M$ replaces) is of course zero. This way we arrive at a profit before allocation of common development cost $\left(C^{D}\right)$ and lump sum. From this (gross) profit we deduct the project's target profit to find the cost allocation the project can carry without eroding its target profit. Target profit is found as the standalone project's profit plus the marginal profit it generates participating in developing and using the module M. Let us briefly focus on $p_{3}$. With budgeted revenue at 800,000 (20,000 units at 40 each) and aggregate unit costs at 270,000 (20,000 units at 13.5 each) gross profit is 530,000 . As standalone project $p_{3}$ creates 100,000 in profit, cf. Table 2 , and contributes additional 40,000 joining projects $p_{1}$ and $p_{2}$ using the common (now more elaborate) module, cf. Table 3. Target profit is therefore 140,000. When deducted from gross profit we calculate that $p_{3}$ can carry costs of 390,000 .

It is worth noticing that the marginal profit of 50,000 using the module $\mathrm{M}$ (in this case less multifunctional than if developed for all six projects) on $p_{1}$ and $p_{2}$ only (cf. Table 3 ), in Table 4 is split evenly between the two projects. It is a joint profit increase and any split between the two projects will do. It should also be noticed that the net sum of what is to be allocated across all projects (last line in Table 4) adds up to total development cost $(2,012,500$, cf. Table 1$)$.

Finally panel A in Table 5 depicts how the project accounts will look after the described allocations, and panel B accounts for the net differences in the various cost categories between using and not using module $\mathrm{M}$.

\subsection{When more financial measures are at play}

The project accounts shown in Table 5, panel A, are sufficient if project managers are evaluated exclusively on the basis of their project profit, here NPV. However, other financial measures may come into play. In our case company, for example, projects are subject to meeting threshold measures on contribution ratio and a ratio of accumulated contribution margin (within the planning horizon) divided by project development costs, i.e. contribution margin/development cost. In this case individual project

Table 2

Profit comparison with and without the common module.

\begin{tabular}{|c|c|c|c|c|c|c|c|c|c|}
\hline & \multicolumn{7}{|c|}{ Before modularization } & \multirow[b]{2}{*}{ New $p_{1-6}$} & \multirow[b]{2}{*}{ Net diff } \\
\hline & $p_{1}$ & $\boldsymbol{p}_{2}$ & $p_{3}$ & $p_{4}$ & $p_{5}$ & $p_{6}$ & Sum $p_{1}-p_{6}$ & & \\
\hline Revenue & $1,250,000$ & $1,350,000$ & 800,000 & 875,000 & 900,000 & 875,000 & $6,050,000$ & $6,050,000$ & 0 \\
\hline Less unit costs & 450,000 & 480,000 & 300,000 & 350,000 & 360,000 & 350,000 & $2,290,000$ & $2,227,500$ & $-62,500$ \\
\hline Less dev't. cost & 500,000 & 450,000 & 400,000 & 350,000 & 300,000 & 100,000 & $2,100,000$ & $2,012,500$ & $-87,500$ \\
\hline$=$ Profit, $\mathrm{NPV}$ & 300,000 & 420,000 & 100,000 & 175,000 & 240,000 & 425,000 & $1,660,000$ & $1,810,000$ & 150,000 \\
\hline
\end{tabular}

Table 3

Profit increase using the common module M.

\begin{tabular}{|c|c|c|c|c|c|c|}
\hline & $p_{1}$ and $p_{2}$ & $\boldsymbol{p}_{3}$ & $\boldsymbol{p}_{4}$ & $\boldsymbol{p}_{5}$ & $\boldsymbol{p}_{6}$ & Sum \\
\hline$\Delta$ profit due to $\mathrm{M}, \Delta^{\mathrm{AM}(\mathrm{M})} P_{i}$ & 50,000 & 40,000 & 30,000 & 20,000 & 10,000 & 150,000 \\
\hline
\end{tabular}

Table 4

Module development cost and lump sum amounts to be allocated individual projects.

\begin{tabular}{|c|c|c|c|c|c|c|c|}
\hline & Notation & $p_{1}$ & $\boldsymbol{p}_{2}$ & $\boldsymbol{p}_{3}$ & $\boldsymbol{p}_{4}$ & $\boldsymbol{p}_{5}$ & $p_{6}$ \\
\hline Revenue & & $1,250,000$ & $1,350,000$ & 800,000 & 875,000 & 900,000 & 875,000 \\
\hline Less unit costs & & 337,500 & 405,000 & 270,000 & 337,500 & 405,000 & 472,500 \\
\hline Less dev't. cost, unique & & 0 & 0 & 0 & 0 & 0 & 0 \\
\hline$=$ Profit before $C^{D}$ and Lump sum & ${ }^{\mathrm{AM}}(\mathrm{M}) P_{\mathrm{i}}^{\mathrm{AAU}}$ & 912,500 & 945,000 & 530,000 & 537,500 & 495,000 & 402,500 \\
\hline Less previous profit & ${ }^{\mathrm{BM}} P_{i}$ & 300,000 & 420,000 & 100,000 & 175,000 & 240,000 & 425,000 \\
\hline Less $\Delta$ profit due to $\mathrm{M}$ & $\Delta^{\mathrm{AM}(\mathrm{M})} P_{i}$ & 25,000 & 25,000 & 40,000 & 30,000 & 20,000 & 10,000 \\
\hline$=$ To be allocated & & 587,500 & 500,000 & 390,000 & 332,500 & 235,000 & $-32,500$ \\
\hline
\end{tabular}


Table 5

Project accounts and net effects of using common module per project and in total.

\begin{tabular}{|c|c|c|c|c|c|c|c|}
\hline & $\boldsymbol{p}_{1}$ & $\boldsymbol{p}_{2}$ & $\boldsymbol{p}_{3}$ & $\boldsymbol{p}_{4}$ & $\boldsymbol{p}_{5}$ & $p_{6}$ & Sum \\
\hline \multicolumn{8}{|c|}{ Panel A: Project accounts using common M } \\
\hline Revenue & $1,250,000$ & $1,350,000$ & 800,000 & 875,000 & 900,000 & 875,000 & $6,050,000$ \\
\hline Unit costs & 337,500 & 405,000 & 270,000 & 337,500 & 405,000 & 472,500 & $2,227,500$ \\
\hline Allocated $C^{\mathrm{D}}$ cost and Lump sum & 587,500 & 500,000 & 390,000 & 332,500 & 235,000 & 0 & $2,045,000$ \\
\hline Lump sum credited & 0 & 0 & 0 & 0 & 0 & $-32,500$ & $-32,500$ \\
\hline Profit, NPV & 325,000 & 445,000 & 140,000 & 205,000 & 260,000 & 435,000 & $1,810,000$ \\
\hline \multicolumn{8}{|l|}{ Panel B: } \\
\hline$\Delta$ unit level costs* & 112,500 & 75,000 & 30,000 & 12,500 & $-45,000$ & $-122,500$ & 62,500 \\
\hline$\Delta$ development costs* & $-87,500$ & $-50,000$ & 10,000 & 17,500 & 65,000 & 100,000 & 55,000 \\
\hline Credit via lump sum & 0 & 0 & 0 & 0 & 0 & 32,500 & 32,500 \\
\hline Net profit change & 25,000 & 25,000 & 40,000 & 30,000 & 20,000 & 10,000 & 150,000 \\
\hline Profit improvement, \% & 8.3 & 6.0 & 40.0 & 17.1 & 8.3 & 2.4 & 9.0 \\
\hline
\end{tabular}

- negative number, - , is a cost increase.

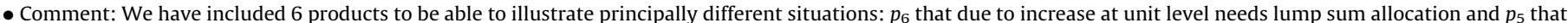
does not; $p_{3}$ and $p_{4}$ which both have decreasing unit level cost but substantial difference in profit increase; $p_{1}$ and $p_{2}$ where share of profit is debatable (see text).

Table 6

Financial performance measure per project and in the aggregate before $\mathrm{M}$, and using $\mathrm{M}$.

\begin{tabular}{|c|c|c|c|c|c|c|c|c|}
\hline & $p_{1}$ & $\boldsymbol{p}_{2}$ & $p_{3}$ & $\boldsymbol{p}_{4}$ & $p_{5}$ & $p_{6}$ & Sum $p_{1}-p_{6}$ & New $p_{1-6}$ \\
\hline Contribution ratio, \% & 64.0 & 64.4 & 62.5 & 60.0 & 60.0 & 60.0 & 62.1 & 63.2 \\
\hline $\mathrm{CM} /$ development cost & 1.6 & 1.9 & 1.3 & 1.5 & 1.8 & 5.3 & 1.8 & 1.9 \\
\hline
\end{tabular}

Table 7

Financial performance measure per project before modularization and in the aggregate after

\begin{tabular}{|c|c|c|c|c|c|c|c|}
\hline & $p_{1}$ & $\boldsymbol{p}_{2}$ & $\boldsymbol{p}_{3}$ & $\boldsymbol{p}_{4}$ & $p_{5}$ & $p_{6}$ & Sum \\
\hline Unit cost less average savings & 437,718 & 466,900 & 291,812 & 340,448 & 350,175 & 340,448 & $2,227,500$ \\
\hline Less unit cost using $\mathrm{M}$ & 337,500 & 405,000 & 270,000 & 337,500 & 405,000 & 472,500 & $2,227,500$ \\
\hline Debiting $(+)$ or crediting $(-)$ unit level & 100,218 & 61,900 & 21,812 & 2,948 & $-54,825$ & $-132,052$ & 0 \\
\hline$=$ Net change at unit level & 12,282 & 13,100 & 8,188 & 9,552 & 9,825 & 9,552 & 62,500 \\
\hline Net change at unit level, \% & 2.7 & 2.7 & 2.7 & 2.7 & 2.7 & 2.7 & 2.7 \\
\hline
\end{tabular}

Table 8

Module development cost and lump sum amounts to be allocated individual projects.

\begin{tabular}{|c|c|c|c|c|c|c|c|}
\hline & $p_{1}$ & $p_{2}$ & $\boldsymbol{p}_{3}$ & $\boldsymbol{p}_{4}$ & $p_{5}$ & $p_{6}$ & Sum \\
\hline Revenue & $1,250,000$ & $1,350,000$ & 800,000 & 875,000 & 900,000 & 875,000 & $6,050,000$ \\
\hline Less unit cost, net & 437,718 & 466,900 & 291,812 & 340,448 & 350,175 & 340,448 & $2,227,500$ \\
\hline$=$ Profit before $C^{D}$ & 812,282 & 883,100 & 508,188 & 534,552 & 549,825 & 534,552 & $3,822,500$ \\
\hline Less previous profit & 300,000 & 420,000 & 100,000 & 175,000 & 240,000 & 425,000 & $1,660,000$ \\
\hline Less $\Delta$ profit due to $\mathrm{M}$ & $-25,000$ & $-25,000$ & $-40,000$ & $-30,000$ & $-20,000$ & $-10,000$ & $-150,000$ \\
\hline$=C^{D}$ to be allocated & 487,282 & 438,100 & 368,188 & 329,552 & 289,825 & 99,552 & $2,012,500$ \\
\hline
\end{tabular}

managers are only motivated to use module $M$ if all three measures do not deteriorate. However, this is not the case with the presented procedure; for example, $p_{5}$ and $p_{6}$ decrease their contribution ratio, and $p_{1}$ and $p_{2}$ deteriorate in the ratio of contribution margin over allocated development cost. We demonstrate that there is a feasible procedure that will show an improvement in all individual project accounts provided that all three financial performance measures are improved across products in the aggregate. This is not shown formally, but only by means of the current example. This revised procedure entails no change in the profit or total costs allocated to each project, only the split between cost categories.

Table 6 shows the new performance measures prior to modularization for individual projects, in the aggregate and across projects after modularization. Numbers are drawn from Table 2, and for $p_{3}$, for example, contribution ratio at $62.5 \%$ results from $(800,000-300,000) / 800,000$ and $\mathrm{CM} /$ development, 1.3 , from
$(800,000-300,000) / 400,000$. Comparing "Sum $p_{1}-p_{6}$ " and "New $p_{1-6}$ " shows that at the aggregate level both new performance measures are improved through modularization.

In our revised procedure we need this to be the case for individual project accounts, too. The total decrease in unit level cost across projects using $\mathrm{M}$ is $2.7 \%$; this we devise to be the benefit for individual projects too, as shown in Table 7 .

Using these new unit level cost numbers, we perform the procedure described in (10) (and Table 4). The result is shown in Table 8.

And the resulting project accounts and performance measures are given in Table 9.

In addition to noticing that there is no change in profit per project (compare the last row of Tables 9 and 5), we also see that we have changed numbers in lump sum allocations at the unit level, and consequently also in allocated numbers of development cost. Lump sum numbers can now be either a credit or a debit 
Table 9

Project accounts, financial performance measures and improvements due to using module M.

\begin{tabular}{|c|c|c|c|c|c|c|c|}
\hline Project accounts using $M$ & $p_{1}$ & $\boldsymbol{p}_{2}$ & $\boldsymbol{p}_{3}$ & $\boldsymbol{p}_{4}$ & $\boldsymbol{p}_{5}$ & $\boldsymbol{p}_{6}$ & Sum \\
\hline Revenue & $1,250,000$ & $1,350,000$ & 800,000 & 875,000 & 900,000 & 875,000 & $6,050,000$ \\
\hline Less unit cost using $M$ & 337,500 & 405,000 & 270,000 & 337,500 & 405,000 & 472,500 & $2,227,500$ \\
\hline Debiting $(+)$, crediting $(-)$ unit level & 100,218 & 61,900 & 21,812 & 2,948 & $-54,825$ & $-132,052$ & 0 \\
\hline$=$ Contribution Margin, $\mathrm{CM}$ & 812,282 & 883,100 & 508,188 & 534,552 & 549,825 & 534,552 & $3,822,500$ \\
\hline Less allocated $C^{\mathrm{D}}$ cost & 487,282 & 438,100 & 368,188 & 329,552 & 289,825 & 99,552 & $2,012,500$ \\
\hline$=$ Profit, NPV & 325,000 & 445,000 & 140,000 & 205,000 & 260,000 & 435,000 & $1,810,000$ \\
\hline \multicolumn{8}{|l|}{ Performance measures: } \\
\hline New CM\% & 65.0 & 65.4 & 63.5 & 61.1 & 61.1 & 61.1 & 63.2 \\
\hline Improvement in CM\%-points & 1.0 & 1.0 & 1.0 & 1.1 & 1.1 & 1.1 & 1.0 \\
\hline $\mathrm{CM} /$ development cost & 1.7 & 2.0 & 1.4 & 1.6 & 1.9 & 5.4 & 1.9 \\
\hline \% Improvement in CM/dev't. cost & 4.2 & 4.3 & 10.4 & 8.1 & 5.4 & 2.3 & 6.1 \\
\hline Profit after using $\mathrm{M}$ & 325,000 & 445,000 & 140,000 & 205,000 & 260,000 & 435,000 & $1,810,000$ \\
\hline Profit improvement, \% & 8.3 & 6.0 & 40.0 & 17.1 & 8.3 & 2.4 & 9.0 \\
\hline
\end{tabular}

(see "Debiting $(+)$, crediting (-) unit level" in Table 9) to accommodate the new additional performance measures. Again we underline that the revised procedure is only feasible when the additional financial measures are improved in the aggregate. If in a given modularization project this is not the case, it represents a serious challenge to the company's set of financial performance measures, since NPV is the superior measure.

\section{Discussing practical challenges with the proposed solution}

In practise we would expect in many situations that we do not have estimates of the marginal profit improvement per participating project, i.e. no calculations of $\Delta^{\mathrm{AM}(\mathrm{M})} P_{i}$, but still an estimate of the total profit increase of using $M$ across the portfolio of projects which is the aggregate number in statement (2) (or the 150,000 for $p_{1}-p_{6}$ in the example). Such situation mirrors the situation for $p_{1}$ and $p_{2}$ in the example for all participating projects. The situation occurs, for example, where the project managers (six in the case) decide not to go into the time and cost consuming effort to calculate the consequences of each project being "in" or "out" using a common module; they only calculate, using (1), with all six or none of the six sharing a common module. Consequently, the upper bound constraints will not come into play in the allocation between projects due to lack of information, and any split that obeys the lower bound constraints will do. One possible split is one sixth $(1 / \mathrm{m})$ to each project. However, we advocate taking into account the specific company's incentive system. In our case with NPV as the main performance measure we recommend an allocation that brings the same NPV percentage increase to each project (this we could have done to $p_{1}$ and $p_{2}$ in the example). Notice that this split is not possible when we know the $\Delta^{\mathrm{AM}(\mathrm{M})} P_{i}$ numbers; knowledge of upper bound constraints rule that out. We also note that the lack of knowledge of marginal profit contribution per product often will be due to information cost discussed below.

In our research on practises in allocating costs of common modules we have come across various allocation procedures in settings with project accounting responsibility. We take up three to highlight why they will not work in decentralized settings.

Example 1. Management had installed the rule that projects sharing a cost-efficient module (satisfies statement (2)) should also equally share the development cost of this module, i.e. if four projects share a module they each carry one fourth of the development cost. This will, however, not work for all projects, as projects that benefit only modestly (but have increasing cost at the unit level) may easily have a profit decrease carrying one fourth of development costs. And it certainly will not work for projects where our procedure would devise crediting a lump sum.

Example 2. Allocation of development cost is done proportional to units used by projects. In principle this procedure runs into the same problems as above.

Example 3. Management tells projects managers that they will be charged less if they use a common module. In cases where it is an already developed module, development costs are sunk costs (and irrelevant), and not included as part of our allocation procedure. It is a "free-of-charge module" costing only unit (and batch) level cost, and it will therefore in many cases be attractive to projects. Our observation on the stated procedure is often where "old" modules carry sunk cost per unit. In situations where it is a new module to be developed the practical allocation setup implemented was similar to examples 1 or 2 .

So far we have not explicitly discussed information cost, referring to cost of cooperating, working out the module possibilities and associated cost estimates. One way of taking this into account is modelling it as a separate variable. We prefer to think of these costs as incorporable in module development already included in the calculations, making $\mathrm{C}^{\mathrm{M}}$ an even more rising function of the number of projects included. In our model it is up to the cooperating project managers to take these costs into account, include them in $\mathrm{C}^{\mathrm{M}}$ and let them be part of the allocation procedure. We acknowledge that these cost estimates are uncertain. However, whether they are more uncertain than other estimates included is difficult to say.

Acknowledging that our solution is a 'cost management system' and not a 'cost accounting system' has implications for who should run the system. The outlined project accounting system is based on purpose-oriented data presentations that serve senior managers in controlling their project managers, and project managers in controlling their projects, i.e. "cost management". The cost accounting system, on the other hand, should provide purpose-neutral (raw) data where objectivity and lack of allocations is the goal (Riebel, 1994). Project accounting, therefore, cannot be part of this when we have common costs (module costs) among projects. There is no objective way in which these can be allocated - like going to more job interviews in one trip and deciding how to allocate the cost among the companies visited. There is no objective way of calculating total cost for a modularized product, only a purpose-oriented one, and this should be one that induces the behaviour we want. Our system, therefore, is run "collectively by the project managers", in practical terms by a management accountant placed as a staff person at the 'product development office', and at the ex ante stage numbers are put into the system when participating project 
managers have agreed on the numbers; and if they cannot agree, there is no common module with the not agreeing project manager. Ex post the numbers first enter the cost accounting system (run by the management accounting department, and with the characteristics of objectivity and lack of allocation just mentioned), and then allocated by the management accountant at the product development office to the project accounts using the procedure described.

Two additional concerns need to be addressed, i.e. 'gaming' and 'uncertainty'. Gaming refers to deliberately biasing information in one's own interest. For example, if a project manager reports into the rule-based calculation a lower cost per unit of the unique component to be substituted (or fewer units than he needs), he will - ceteris paribus - increase his probability of receiving a lump sum or at least 'a discount' on his share of development cost. In judging the potential success of this gaming it has to be remembered that the data input is changes to previous NPV calculations of the project, known to the other project managers, making the tactics less pursuable. In addition, it is less likely that he will be part of the modularization project due to the calculation in statement (1), and ultimately he will be less well off at the ex post stage.

'Uncertainty', of course, is omnipresent, not least in product development. And we have not included it in our model which is a limitation. On this subject we have taken a more pragmatic position. The main reason is that in our experience budgets, including new product development budgets and forecast, in their economics are presented in the 'most likely' version supplemented with a number of sensitivity analyses on the financial results and other critical KPIs; rarely though with probabilities and statistical distributions included. In such a context we expect our project managers to take uncertainty into account using sensitivity analyses and determine the critical values where the benefit of joining or not joining in sharing a module shifts for their project. However, in the end a decision must be made simultaneously with the other project managers - and from that day forward this is what enters our solution.

\section{Conclusion}

We have argued that OM models on modularity (like Ramdas et al. (2003)) will encounter difficulties in getting implemented in practise. Dysfunctional accounting systems will act as barriers in that they at the level of the individual project distort the projects' contribution to product portfolio as a whole when common modules are at play. Typically cost-efficient modules through prevailing heuristic cost allocations benefit some projects but hamper others that actually contribute to the modules' cost efficiency. This has the consequence that relevant information is only found in the aggregate and at the organizational top. This prevents decentralized decision-making and project account responsibility.

To solve this we identified the boundaries within which allocations rationally can take place so that profitability at the project and portfolio level is aligned. Within these boundaries we developed a rule-based allocation procedure that encourages project managers, on their own initiative, to cooperate in an attempt to exploit profitability of modularization.

We also found that to maintain responsibility accounting and the benefits of accountability and motivation inherent in this management technique, it can be necessary to adjust the cost allocations between cost-hierarchy levels to accommodate additional financial performance measures used.

Our rule-based allocation model has some limitations. First, we have not explicitly taken into account situations where the modularization effort is conducted across company jurisdictions, i.e. cooperation in modularization between independent companies in networks or supply chains. However, in some contractual situations it becomes simpler, for example, in situations where the supplier quotes different unit prices of the common module as a function of the degree of functionality and volume. This simplification entails that no allocation of development cost is involved then; and this can be dealt within the current procedure. The optimal degree of modularization will be different to inhouse modularization though, since some degree of profit is allocated the supplier. In other contractual situations, for example, where more suppliers and various supplier activities are paid for separately (e.g. development cost) more research is needed.

Another limitation is that our procedure is static, in the sense that we look at simultaneous product development projects. Lack of dynamism is also referred to by Fisher et al. (1999:312 ff.) stating that the "challenge of component sharing is increased as the decision is viewed dynamically. In most industrial situations, there already exists a portfolio of products and the managerial problem is to decide which components to reuse, which components to replace, and which new components to develop. This problem is complex and deserves further research attention". Our model is not sensitive to decisions concerning reuse and replacement of existing components/modules, though-past development costs of these are 'sunk' and thus irrelevant to decisions and allocations. However, our model is sensitive to module needs of future products beyond the company's product portfolio planning horizon. One way forward might be to incorporate real options theory since the flexibility achieved by modularization has a value which can be estimated using this theory (e.g. Baldwin and Clark, 2000; Gaynor and Bradner, 2001).

We acknowledge the logic and complexity captured in the OM models on component/module sharing and the insights they bring to management's decision-making processes. At the same time, though, we propose further research into the organizational intricacies in which these models are to be implemented. Such research will have to bridge theoretical domains, as we have tried to bridge $\mathrm{OM}$ and management accounting in this paper. We believe that other domains, like organization, finance and marketing, may also benefit from bridging with $\mathrm{OM}$-and there is certainly room for more bridging from the management accounting domain too.

\section{References}

Anderson, S.W., 1995. Measuring the impact of product mix heterogeneity on manufacturing cost. The Accounting Review 79 (3), 363-387.

Antonio, K.W.L., Yam, R.C.M., Tang, E., 2007. The impacts of product modularity on competitive capabilities and performance: an empirical study. International Journal of Production Economics 105 (1), 1-20.

Balakrishnan, A., Geunes, J., 2000. Requirements planning with substitutions: exploiting bill-of-materials flexibility in production planning. Manufacturing \& Service Operations Management 2 (2), 166-185

Baldwin, C., Clark, K., 2000. Design rules; the power of modularity. The MIT Press.

Banker, R.D., Potter, G., Schroeder, R.G., 1995. An empirical analysis of manufacturing overhead cost drivers. Journal of Accounting \& Economics 19 (1), $115-137$.

Brun, A., Zorzini, 2009. Evaluation of product customization strategies through modularization and postponement. International Journal of Production Economics 120 (1), 205-220.

Brun, A., Capra, E., Miragliotta, G., 2009. VRP revisited: the impact of behavioural costs in balancing standardization and variety. International Journal of Production Economics 117 (1), 16-29.

Collier, D.A., 1982. Aggregate safety stock levels and component part commonality. Management Science 28 (10), 1296-1303.

Desai, P., Kekre, S., Radhakrishnan, S., Srinivasan, K., 2001. Product differentiation and commonality in design: balancing revenue and cost drivers. Management Science 47 (1), 37-51.

Doran, D., 2003. Supply chain implications of modularization. International Journal of Operations \& Production Management 23 (3), 316-326. 
Doran, D., Hill, A., Hwang, K.-S., Jacob, G., 2007. Supply chain modularisation: cases from the French automobile industry. International Journal of Production Economics 106 (1), 2-11.

Eynan, A., Rosenblatt, M.J., 1996. Components commonality effects on inventory costs. IEE Transactions 28 (2), 93-104.

Fisher, M., Ramdas, K., Ulrich, K., 1999. Component sharing in the management of product variety: a study of automotive breaking systems. Management Science 45 (3), 297-315.

Fixson, S.K., Clark, J.P., 2002. On the link between modularity and cost; A methodology to assess cost implications of product architecture differences. IEEE International Engineering Management Conference 1, 131-136.

Fixson, S.K., 2005. Product architecture assessment: a tool to link product, process, and supply chain design decisions. Journal of Operations Management 23 (3-4), 345-369.

Gaynor, M., Bradner, S., 2001. The real options approach to standardization. In: Proceedings of the Hawaii International Conference on System Sciences.

Gomes, P.J., Joglekar, N.R., 2008. Linking modularity with problem solving and coordination efforts. Managerial and Decision Economics 29 (5), 443-457.

Heese, H.S., Swaminathan, J.M., 2006. Product line design with component commonality and cost-reduction effort. Manufacturing \& Service Operations Management 8 (2), 206-219.

Heikkilä, J., Karjalainen, T.-M., Martio, A., Niininen, P., 2002. Products and modularity. TAI Research Centre, Helsinki University of Technology.

Hillier, M.S., 2002. Using commonality as backup safety stock. European Journal of Operational Research 136 (2), 353-365.

Jans, R., Degraeve, Z., Schepens, L., 2008. Analysis of an industrial component commonality problem. European Journal of Operational Research 186 (2), 801-811.

Kaplan, R.S., Cooper, R., 1998. Cost and Effect: Using integrated cost systems to drive profitability and performance. Harvard Business School Press, Boston, USA, Boston, MA.

Kim, K., Chhajed, D., 2000. Commonality in product design: cost saving, valuation change and cannibalization. European Journal of Operational Research 125 (3), 602-621.

Kim, K., Chhajed, D., 2001. An experimental investigation of valuation change due to commonality in vertical product line extension. Journal of Product Innovation Management 18 (4), 219-230.

Krishnan, V., Singh, R., Tirupati, D., 1999. A model-based approach for planning and developing a family of technology-based products. Manufacturing and Service Operations Management 1 (2), 132-156.

Krishnan, V., Gupta, S., 2001. Appropriateness and impact of platform-based product development. Management Science 47 (1), 52-68.

Labro, E., 2004. The cost effects of component commonality: a literature review through a management accounting lens. Manufacturing \& Service Operations Management 6 (2), 358-367.

Lee, H.L., Tang, C.S., 1997. Modelling the costs and benefits of delayed product differentiation. Management Science 43 (1), 40-53.
Miller, J.G., Vollman, T.E., 1985. The hidden factory. Harvard Business Review 63 (5), 142-150.

Nobelius, D., Sundgren, N., 2002. Managerial issues in parts sharing among product development projects: a case study. Journal of Engineering and Technology Management 19 (1), 59-73.

Nobeoka, K., Cusumano, M., 1997. Multiproject strategy and sales growth: the benefits of rapid design transfer in new product development. Strategic Management Journal 18 (3), 169-186.

Ramdas, K., Sawhney, M.S., 2001. A cross-functional approach to evaluating multiple line extensions for assembled products. Management Science 47 (1), 22-36.

Ramdas, K., 2003. Managing product variety: an integrative review and research directions. Production and Operations Management 12 (1), 79-101.

Ramdas, K., Fisher, M., Ulrich, K., 2003. Managing variety for assembled products: modelling component systems sharing. Manufacturing \& Service Operations Management 5 (2), 142-156.

Riebel, P., 1994. Core features of the "Einzelkosten- und Deckungsbeitragsrechnung". European Accounting Review 3 (3), 515-543.

Robertson, D., Ulrich, K., 1998. Planning for product platforms. Sloan Management Review 39 (4), 19-31.

Salvador, F., 2007. Toward a product system modularity construct: literature review and reconceptualization. IEEE Transactions on Engineering Management 54 (2), 219-240.

Salvador, F., Forza, C., Rungtusanatham, M., 2002. Modularity, product variety, production volume, and component sourcing: theorizing beyond generic prescriptions. Journal of Operations Management 20 (5), 549-575.

Sanchez, R., 1999. Modular architectures in the marketing process. Journal of Marketing 63 (Special Issue), 92-111.

Sanderson, S., Uzumeri, M., 1995. Managing product families: the case of the Sony Walkman. Research Policy 24 (5), 761-782.

Simon, H., 1976. Administrative behaviour: a study of decision-making processes in administrative situations, Third edition The Free Press, New York.

Starr, M., 1965. Modular production-a new concept. Harvard Business Review 43 (6), 131-142.

Starr, M., 2010. Modular production-a 45-year-old concept. International Journal of Operations \& Production Management 30 (1), 7-19.

Swaminathan, J.M., Tayur, S.R., 1999. Designing task assembly and using vanilla boxes to delay product differentiation: an approach for managing product variety. In: Ho, T.-H., Tang, C.S. (Eds.), Product variety management. Research advances. Kluwer Academic Publishers, Boston, MA.

Thonemann, U., Brandeau, M., 2000. Optimal commonality in component design. Operations Research 48 (1), 1-19.

Thyssen, J., Israelsen, P., Jørgensen, B., 2006. Activity based costing as a method for assessing the economics of modularization-a case study and beyond. International Journal of Production Economics 103 (1), 252-270.

Zhou, L., Grubbström, R.W., 2004. Analysis of the effect of commonality in multilevel inventory systems applying MRP theory. International Journal of Production Economics 90 (2), 251-263. 